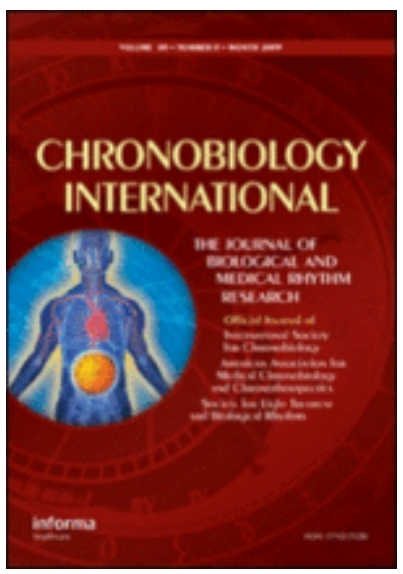

\title{
The effect of urbanization on sleep, sleep/wake routine, and metabolic health of residents in the Amazon region of Brazil.
}

\begin{tabular}{|c|c|}
\hline Journal: & Chronobiology International \\
\hline Manuscript ID & LCBI-2019-0277.R3 \\
\hline Manuscript Type: & Report \\
\hline $\begin{array}{l}\text { Date Submitted by the } \\
\text { Author: }\end{array}$ & $\mathrm{n} / \mathrm{a}$ \\
\hline Complete List of Authors: & $\begin{array}{l}\text { Martins, Andressa; University of Sao Paulo } \\
\text { Isherwood, Cheryl; University of Surrey, Chronobiology } \\
\text { Vasconcelos, Suleima; Federal University of Acre, } \\
\text { Lowden, Arne; Stockholm University, Stress Research Institute } \\
\text { Skene, Debra; University of Surrey, Chronobiology } \\
\text { Moreno, Claudia; University of Sao Paulo, Environmental Health; } \\
\text { Stockholm University, Stress Research Institute }\end{array}$ \\
\hline Keywords: & $\begin{array}{l}\text { sleep, metabolic parameters, metabolic diseases, urban, rural, natural } \\
\text { light exposure, circadian routine }\end{array}$ \\
\hline
\end{tabular}

\section{SCHOLARONE" \\ Manuscripts}


Selected Proceedings: Shiftwork 2019

The effect of urbanization on sleep, sleep/wake routine, and metabolic health of residents in the Amazon region of Brazil.

Andressa J. Martins a, Cheryl M. Isherwood ${ }^{b}$, Suleima P. Vasconcelos ${ }^{c}$, Arne Lowden $^{d}$, Debra J. Skene ${ }^{b}$, Claudia R.C. Moreno ${ }^{a, d}$.

a School of Public Health, University of São Paulo, São Paulo, Brazil. b Faculty of Health \& Medical Sciences, University of Surrey, UK. ${ }^{c}$ Center of Health and Sport Sciences, Federal University of Acre. d Stress Research Institute, University of Stockholm, Stockholm, Sweden.

Corresponding author (Claudia RC Moreno) at:

School of Public Health, University of São Paulo, Av. Dr. Arnaldo, 715, Cerqueira César, 01246-904, São Paulo, São Paulo, Brazil. Phone: +55 11 3061-7905.

E-mail address: crmoreno@usp.br (Claudia R.C. Moreno) 


\begin{abstract}
Studying communities with different levels of urbanization may further the understanding of risk factors underlying metabolic diseases. The present study is unique by comprising detailed assessment of sleep and activity, biological rhythms, and metabolic factors of men from the same geographical location and place of birth that reside in different, rural vs. town, stages of urbanization. Sleep patterns, activity, and metabolic indicators in two groups (rural, $n=22$ and town/urban, $\mathrm{n}=20$ ) of men residing in an Amazonian community (Xapuri, Acre, Brazil) were compared. Sociodemographic, anthropometric, and metabolic variables -- fasting glucose, insulin resistance, triglycerides, total HDL cholesterol, LDL cholesterol, and VLDL cholesterol -- were assessed. Sleep patterns, light exposure, and physical activity levels were additionally assessed by actigraphy, plus daily activities were recorded in diaries for 10 days. Town/urban dwellers were found to have significantly higher body weight, fasting glucose, insulin levels, and insulin resistance than rural dwellers, whereas triglycerides levels were similar. Town/Urban dwellers had shorter sleep duration $(p<0.01)$ and later sleep onset and offset times $(p=0.01)$. Our findings show an association between stage of urbanization and presence of risk factors for metabolic disorders, such as overweight, insulin resistance, increased glucose levels, short sleep duration, and less natural light exposure during work times.
\end{abstract}

Keywords: urban; rural; metabolic diseases; metabolic parameters; sleep; natural light exposure, circadian routine. 


\section{INTRODUCTION}

Non-communicable diseases are a significant concern in the context of global public health of both developed and developing countries (Ali et al. 2015). In this regard, urbanization is associated with a lifestyle of reduced physical activity, energy-dense nutrient-poor diets, sedentary work, extended exposure to artificial light, and reduced sleep duration (Caballero 2005). In turn, these lifestyle factors are associated with risk factors for diseases of civilization, e,g., dyslipidemias, obesity, hypertension, and insulin resistance (Popkin 2009). Sleep restriction, itself, has been linked with compromised metabolic health (Christou et al. 2019; Farr \& Mantzoros 2018) in the form of disrupted glucose metabolism (Potter et al. 2016) and reduced insulin sensitivity (Spiegel et al. 1999; Roenneberg et al. 2012).

The proportion of the population residing in urban areas globally has increased from $13 \%$ in the early 20 th century to almost $50 \%$ in 2005 (Kearney 2010), and according to the World Cities Report, published by the United Nations in $2016,54 \%$ of the world's population lives in urban areas. The report also notes this trend has remained steady for the past $20 \mathrm{y}$, especially in developing nations, such as Asian, Latin American, and African countries (United Nations Human Settlements Program 2016). Recent research studies comparing urban versus rural and hunter-gatherer communities highlight the relationship between the urbanization of small cities and sleep quality (Beale et al. 2017; De la Iglesia et al. 2015; Moreno et al. 2015). Moreno et al. (2015) reported Amazonian rubber tappers (rural dwellers) with access to electricity slept for less time than those without electricity. De la Iglesia et al. (2015) also reported shorter sleep duration in those with access to electricity among two 
indigenous communities of hunter-gatherers in Argentina. More recently, Beale et al. (2017) found later sleep start times in urban dwellers compared to rural dwellers in Mozambique. In addition, urban vs. rural residence has an effect on the diet-sleep association; for example, relative intake of protein was found to be inversely associated with sleep duration, but only in rural residents (Liu et al. 2018). The association between sleep and diet may have an effect on metabolic indicators. A study conducted on a rural Brazilian population revealed poor sleep quality to be independently associated with a poorer lipid profile, suggesting poor sleep quality may be an epiphenomenon of other sleep disturbances (Geovanini et al. 2019).

Several published studies have demonstrated a relationship between elevated body mass index (BMI) and short sleep duration and later sleep timing (Lucassen et al. 2013; Roenneberg et al. 2012). Both animal models and human studies have shown that exposure to light can modulate metabolism, especially the appetite regulating hormones, for example, leptin and ghrelin as well as increase body weight and adiposity (Figueiro et al. 2012; Fonken et al. 2010).

Greater knowledge of the sleep patterns and nutrition among communities that undergo urbanization, in comparison with nearby rural communities, is fundamental to better understanding the impact of urbanization on human health, especially in the context of non-communicable diseases. Northern Brazil, particularly the Amazon region, is the ideal environment for this type of study. Its population residing in rural areas is without access to electricity and the nearby small towns are in the initial stages of industrialization with access to modern industrialized facilities. There has been very low migration in 
the area in comparison to the Southern regions of Brazil. Furthermore, this location is around latitude $10^{\circ}$, which means low variation in the daytime natural photoperiod duration during the year.

From the above scenario, the present study is unique by comprising detailed assessment of sleep and activity, biological rhythms, and metabolic factors, making it possible to compare two similar groups (same geographical location, place of birth) in different stages of urbanization (rural vs. town/urban dwellers).

\section{METHODS}

Study sample and design. We conducted a cross-sectional study of two similar groups (geographical location, place of birth) in different stages of urbanization (rural vs. town/urban dwellers). Sociodemographic data, lifestyle habits, anthropometry, nutritional status, and metabolic indicators were collected. The study was conducted on two occasions, between September and October 2015 and July and August 2016.

The total sample of the study $(n=42)$ consisted of two groups: 1$)$ rural dwellers $(n=22)$, who were residents in the extractive reserve of Chico Mendes located in the municipality of Xapuri; 2) town dwellers $(n=20)$, who lived nearby in the town of Xapuri (Latitude: $10^{\circ} 39^{\prime} 06 " \mathrm{~S}$; Longitude: $68^{\circ} 30^{\prime} 16^{\prime \prime} \mathrm{W}$ ), and were employed in the education and services sectors. Both the rural and town groups were composed of males with mean age of $41.6(S D=10.9)$ and 38.8 y $(S D=8.2)$, respectively. Both groups had lived all their lives in the area, and no former rural workers comprised the urban sample. 
The state of Acre, located in the northern region of Brazil, has 16,091 inhabitants in an area of $5,347,446 \mathrm{~km}^{2}$, of whom $5,761(36 \%)$ reside in the rural area and 10,330 (64\%) in the urban area (IBGE 2010).

Inclusion criteria for the town dwellers were: male, life and work routine of daytime activity and nighttime sleep, and residing in urban (town) setting. The inclusion criteria for the rural dwellers were: male sex, residing and working in the extractive reserve (activities such as extraction of latex, nuts, subsistence agriculture, and raising small animals) with access to electricity in their homes. School teachers from the local public school were invited to participate as town dwellers, and rural dwellers were randomly invited. Females, shift-workers, and males with pre-existing self-reported sleep disorders were excluded.

\section{Variables}

\section{Socio-demographic and lifestyle questionnaire}

Data on socio-demographic aspects were collected, such as age, sex, education, marital status, and number of persons per residence, number of children $<18$ y of age, and life habits (physical activity, smoking, and alcohol intake).

\section{Nutritional Status}

Nutritional status was evaluated by measuring BMI, body fat percentage, and waist circumference. According to the recommendation of the World Health Organization (WHO 2000), BMI was categorized as follows: $<18 \mathrm{~kg} / \mathrm{m}^{2}=$ low weight; $\geq 18.5 \mathrm{~kg} / \mathrm{m}^{2}$ to $<25 \mathrm{~kg} / \mathrm{m}^{2}=$ eutrophy; $\geq 25 \mathrm{~kg} / \mathrm{m}^{2}$ to $<30 \mathrm{~kg} / \mathrm{m}^{2}=$ overweight; $\geq 30 \mathrm{~kg} / \mathrm{m}^{2}$ = obese. Following the proposal by the Brazilian Society 
of Cardiology in 2013, we used a waist circumference $\geq 90 \mathrm{~cm}$ in men as constituting abdominal obesity indicative of risk for metabolic morbidities. Body fat index, visceral fat index, and metabolic age were calculated using the Tanita $®(B C 543)$ digital scale.

\section{Metabolic Parameters}

A fasting (morning) blood sample for the measurement of glucose, insulin, triglycerides, total cholesterol, HDL, LDL, and VLDL cholesterol was collected by a trained nurse and transported for analysis to an authorized laboratory according to all transport protocols of biological material in the state capital of Acre, Rio Branco. Triglycerides, total cholesterol, and LDL-cholesterol ranges were established by the Brazilian Dyslipidemias Directive; high $\geq 150$ $\mathrm{mg} / \mathrm{dL}$ (triglycerides), $200 \mathrm{mg} / \mathrm{dL}$ (total cholesterol), $\geq 100 \mathrm{mg} / \mathrm{dL}$ (LDLcholesterol); low $<40 \mathrm{mg} / \mathrm{dL}$ (HDL-cholesterol) (Brazilian Society of Cardiology 2013). The 2016 reference values of the Brazilian Diabetes Society were used to categorize fasting glycemia. Insulin resistance was calculated using the HOMA-IR (Homeostasis Model Assessment). Values >2.71 were considered high for the Brazilian population according to Geloneze et al. (2006).

\section{Activity and Sleep}

A daily activities diary was completed by the study participants with the aid of the researcher when necessary. The diary consisted of a $24 \mathrm{~h}$ schedule divided into 15 min intervals, which presented the following activities: work, transportation, sleep, meal or snack, play, and other leisure activities. Participants wore a light-activity monitor on their non-dominant wrist for 10 
consecutive days to investigate sleep patterns, light exposure, and physical activity level. The light-activity monitor contains an accelerometer to record activity levels and light per $60 \mathrm{~s}$ epochs (ActTrust Condor Instruments). Raw data were checked and corrected for inconsistencies according to the information contained in the activities diary and subsequently edited using Philips Actware 6.0.5 software (Philips Respironics®). After editing all of the actograms, the variables related to sleep for work days and days off were estimated. The variables analyzed were: sleep onset time, wake up time, sleep length, and time of midsleep.

\section{Statistical Analysis}

The Shapiro Wilk test was used to evaluate the distribution of the variables. The Fisher's exact test was used to verify associations between the following categorical variables: marital status, education, presence of children $<18$ y, alcohol intake, smoking, physical activity, BMI, waist circumference, fasting glucose, triglycerides, total cholesterol, LDL-cholesterol, HDLcholesterol, and VLDL-cholesterol.

Student's t-tests (or a non-parametric test when data were not normally distributed) were performed for independent samples on normally distributed data to compare between rural and town dwellers the variables of age, BMI, waist circumference, body fat, visceral fat, muscle mass, metabolic age, fasting glucose, fasting insulin, triglycerides, total cholesterol, LDL-cholesterol, HDLcholesterol, and energy (Kcal).

Repeated measures ANOVA tested main effects and the interaction between day of week (work days and days off) and location (rural/town) on sleep onset, wake up time, midsleep time, and sleep duration, as well as the 
main effects between location and time-of-day (hour) of physical activity and light exposure on work days and days off. Spearman`s correlation tests were performed between BMI and energy intake (Kcal) of rural and urban participants. The Stata14 software program (Stata Corporation, College Station, TX, USA) was used for all statistical analyses. A p-value $<0.05$ level of statistical significance was adopted for all tests.

\section{Ethical Aspects}

The study was approved by the Research Ethics Committee of the Faculty of Public Health of the University of São Paulo (CAAE: 44860515.0.0000.5421), and was conducted in accordance with the ethical standards established by the National Health Council (Resolution 466 of December 12, 2012) (Portaluppi et al., 2010). Volunteers, after being informed about the research objectives, provided signed informed consent.

\section{RESULTS}

Urban/town dwellers had higher levels of education than rural dwellers $(p<0.001)$ and smoked less; $36.4 \%$ of rural dwellers were smokers vs. $5 \%$ of town dwellers; $p<0.05$. No differences between the two groups were observed regarding marital status, having children at home, or alcohol consumption. However, there were differences regarding eating behavior, with higher carbohydrate consumption among rural dwellers in comparison to urban dwellers (details of eating behavior have been published elsewhere; Tiuganji et al., 2020). Moreover, urban/town dwellers had significantly higher $(p<0.05)$ 
values of body fat, and consequently more indicators for overweight, obesity, and metabolic risks (Table 1 and Figures $1 \mathrm{~A}-\mathrm{E}$ ).

\section{INSERT TABLE 1}

\section{INSERT FIGURES 1A-E}

Town dwellers had significantly higher $(p<0.05)$ fasting glucose levels, fasting insulin, and HOMA-IR index compared to rural dwellers (Table 1 and Figures 2B-D). No statistically significant differences were observed between the levels of triglycerides, total cholesterol, HDL- cholesterol, LDL-cholesterol, and VLDL-cholesterol between the town and rural dwellers (Figure 2A). However, as depicted in Figure 1, there was a trend of higher values in these parameters among town dwellers, except for HDL-cholesterol, which was higher among rural dwellers, as a protective factor against cardiovascular diseases.

\section{INSERT FIGURES 2A-D}

Town dwellers slept for shorter duration $(F=15.30, p=0.0004)$ during work days, had later sleep onset $(F=28.30, p<0.0001 ; F=23.18, p<0.0001)$, later wake up time $(F=5.11, p=0.0299 ; F=25.15, p<0.0001)$, and later midsleep time $(F=25,89, p<0.0001 ; F=41,99, p<0.0001)$ during work and days off (Figure 3 ).

\section{INSERT FIGURE 3}


Participants in rural areas were exposed to natural light since their work activities occurred in the field, with activities related to land cultivation management. Among the urban participants, there was less exposure to natural light, since their work activities took place indoors in enclosed spaces, such as schools and public offices (supplemental material). In both groups, as expected, there were higher levels of activity during the day; however, for the rural dwellers, higher activity levels were observed compared to the urban dwellers, with significant differences between the two groups during work days. No significant differences in light exposure were found between the two groups (rural and town dwellers) on days off (supplemental material). However, rural dwellers were significantly more active than town dwellers on their days off.

\section{DISCUSSION}

Modernization and urbanization is ongoing now in many distant regions and communities in Brazil, bringing with them changes in life habits that can impact health, including increasing risk for metabolic and cardiovascular diseases, plus reduction of quality of life. According to Malik and collaborators (2013), the negative consequences of an urbanized lifestyle are the result of profound changes related to technological advances, intense mechanization, alteration of housing environment, broader availability of food options, increased sleep deprivation, and greater availability of social activities during the nighttime. According to the authors, all these aspects collectively impact quality of the diet, significantly reduce daily energy expenditure, and contribute to increased obesity. 
Here, we describe the differences between urban/town and rural cohorts in aspects related to nutritional status, as well as metabolic factors associated with the risk of non-communicable diseases and sleep quality. Our findings emphasize the prevalence of overweight and obesity among town residents, as well as high levels of biochemical markers -- fasting glucose, fasting insulin, and insulin resistance by the HOMA-IR index -- indicative of metabolic diseases. These findings can contribute to public policies that implement recommendations from the NOVA food classification system (Monteiro et al. 2018) regarding avoidance of ultra-processed foods, which are consumed in high amount by urban residents.

Previous studies have shown a strong relationship between urbanization and the presence of non-communicable metabolic and cardiovascular diseases, in terms of their associated risk factors, such as overweight, high blood pressure, changes in serum lipids, and insulin resistance (Monda et al. 2007; Novak et al. 2012;). Such non-communicable diseases have huge impact on socioeconomic development, especially in developing countries, as they affect the economically active population, resulting in lost productivity (Alwan \& Maclean 2009).

In contrast, our findings reveal the body weight and metabolic indicators of rural inhabitants are in the normal range. Rural dwellers, in comparison with town dwellers, were thus healthier despite having a higher proportion of smokers and doing less physical activity during leisure time. The literature reports that rural work, which in itself requires greater physical strength, may contribute significantly to a lower prevalence of cardio-metabolic risk factors among rural communities (Obirikorang et al. 2015). Nevertheless, the literature 
also shows a relationship between intense physical effort of rural work and quality of sleep. Martins et al. (2016) in a study of a similar rural population from the Amazon found an increased prevalence of musculoskeletal pain due to work effort that was associated with poorer sleep. Moreno et al. (2016) also showed rural work is an important predictor of sleep problems and musculoskeletal pain.

The sleep patterns of the urban dwellers in comparison to rural dwellers were characterized by delayed sleep onset and wake up time, as well as shorter sleep duration. Although both groups have electricity in their homes, the town is more illuminated and has more nighttime activities than the rural area. However, the quality of sleep of the rural residents was worse, as reported elsewhere (Martins et al. 2016). Beijamini et al. (2016) also found high prevalence $(34.9 \%)$ of poor sleep quality in a Brazilian rural population. High prevalence of poor sleep quality thus appears to be a common finding in rural communities marked by strenuous work activities. Another study in a rural African community also found worse sleep quality among rural residents due to poor sleeping conditions and intense work activity (Beale et al. 2017). In addition, town residents with access to electricity also exhibited delays in sleep onset, similar to that found in the current study. Beale et al. (2017) also point out that some aspects of the urban environment may have beneficial effects on sleep, such as access to more comfortable sleeping places, safer homes, more comfortable room temperature, etc.

In our study, the jobs of town residents were less laborious and required less physical effort, thereby corroborating the above-discussed finding of recent publications. However, even in the face of these possible benefits generated by 
urbanization, our findings corroborate the growing literature showing shorter sleep duration, later sleep onset, later wake up time, and less light exposure during work days in town/city dwellers.

Patel and Hu (2008) in their systematic review showed shorter sleep duration increased the risk of obesity. It is well described in the literature that sleep deprivation/restriction reduces leptin levels and increases ghrelin levels, thus altering metabolism and satiety and contributing to increased obesity (Patel et al. 2006; Spiegel et al. 2004).

In addition to sleep, exposure to light has been a recurring research topic associated with obesity. According to Reid and collaborators (2014), exposure to moderate light levels at biologically appropriate times may influence body weight regardless of sleep duration and time of sleep onset. Obayashi et al. (2016), in a cohort study, demonstrated that exposure to light during the night and reduction of light exposure throughout the day were associated with an increase in obesity indicators in an elderly population, regardless of sleep duration, sleep onset, and sleep disorders. The 10 y followup assessment detected an estimated 10\% increase in BMI and 10.2\% increase in waist:hip ratio. Increased nocturnal light and reduced natural daylight exposure are common features of modern society (Lunn et al. 2017), and in combination may be an important risk factor for obesity.

One of the possible mechanisms that may explain the direct relationship between light exposure and body weight, independent of caloric intake, may be the direct influence of light on hormone synthesis, such as melatonin. Exposure to daylight may alter nocturnal levels of melatonin and the sensitivity of the circadian oscillator to light (Chang et al. 2011; Obayashi et al. 
2012; Smith et al. 2004). These factors may influence energy metabolism. Changes in melatonin concentrations may also affect insulin sensitivity (Mcmullan et al. 2013; Peschke et al. 2013; Zanuto et al. 2013). These findings also corroborate the results of our research, since hyperglycemia and higher insulin resistance was observed among the town residents.

Another important aspect to be discussed in the genesis of weight gain is the timing of food intake (McHill et al. 2017). Although timing of food intake is not discussed here, several studies, both in humans and in animal models, state that eating foods at inappropriate times when they should be reserved for sleep can lead to overweight and metabolic diseases (Arble et al. 2009; Baron et al. 2013; Colles et al. 2007; Salgado-Delgado et al. 2010).

Some lifestyle characteristics found in town/urban settings may contribute to the excess weight observed in the town dwellers. In contrast, some aspects of urbanization, such as greater access to health and education, could contribute positively to the improvement of the issues discussed above. However, in developing countries such as Brazil, the growth of urban areas occurs rapidly, often without detailed planning and without basic infrastructures, so that the problems of urbanization impact especially the poorest populations of these regions (Malik et al. 2013; Popkin 2009). Xu et al. (2014) pointed out this aspect of rapid growth in a study of rural and urban populations in Shaanxi Province, China that is undergoing accelerated urbanization. The study found increased risk for metabolic syndrome among rural residents as a result of the recent sociodemographic and lifestyle changes. The authors discussed the fact that rural communities in the process of urbanization share the same problems as cities, such as soil, water and air contamination, but do not have access to 
the same facilities, such as hospitals, health care, adequate housing, education, and places for recreation and leisure activities.

In conclusion, our findings show an association between town/urban residence and the presence of risk factors for metabolic disorders, such as overweight, insulin resistance, increased glucose levels, short sleep duration, and reduced natural light exposure during work times. However, in a developing country like Brazil, rural populations seem to exhibit poorer sleep quality and adoption of some unhealthy lifestyle`s practices, like smoking (Geovanini et al. 2019; Martins et al. 2016).

This overview provides a dimension of the new challenges to individual and public health with advancement of the contemporary urbanized lifestyle within Brazil and its potential health risks over and above the existing health problems of rural areas, which arise from poor access to basic health care, low educational level, low income, and inadequate working conditions.

\section{Conflicts of interest statement}

We declare no conflicts of interest.

\section{Acknowledgements}

We would like to extend our thanks for the financial support provided by the Coordenação de Aperfeiçoamento de Pessoal de Nível Superior (CAPES); Fundação de Amparo à Pesquisa do Estado de São Paulo (FAPESP \#2016/09582-0); Newton Fund-São Paulo Research Foundation (FAPESP), the National Council for the State Funding Agencies (CONFAP) and UK Academies, Short-term Visiting Researcher (FAPESP \#2014/50977-3); Santander University Awards for Staff Mobility and FHMS ADI Travel Grant, University of Surrey - support for mini-sabbatical to Brazil; Santander Postgraduate Travel Award for C.M. Isherwood to University of Sao Paulo, Sao Paulo. Brazil. 


\section{REFERENCES}

1. Ali MK, Jaacks LM, Kowalski AJ, Siegel KR, Ezzati M. 2015. Noncommunicable diseases: three decades of global data show a mixture of increases and decreases in mortality rates. Health Aff. 34(9):1444-55.

2. Alwan A, MacLean DR. 2009. A review of non-communicable disease in low- and middle-income countries. Int Health. 1:3-9.

3. Arble DM, Bass J, Laposky AD, Vitaterna MH, Turek FW. 2009. Circadian timing of food intake contributes to weight gain. Obesity (Silver Spring). 17:2100-2.

4. Baron KG, Reid KJ, Horn LV, Zee PC. 2013. Contribution of evening macronutrient intake to total caloric intake and body mass index. Appetite. 60:246-51.

5. Beale AD, Pedrazzoli M, Gonçalves BSB, Beijamini F, Duarte NE, Egan KJ, Knutson KL, von Schantz M, Roden LC. 2017. Comparison between an African town and a neighbouring village shows delayed, but not decreased, sleep during the early stages of urbanisation. Scientific Reports. 7(1):5697. doi:10.1038/s41598-017-05712-3.

6. Beijamini F, Knutson KL, Lorenzi-Filho G, Egan KJ, Taporoski TP, De Paula LKG, Negrão AB, Horimoto ARVR, Duarte NE, Vallada $\mathrm{H}$, et al. 2016. Timing and quality of sleep in a rural Brazilian family-based cohort, the Baependi Heart Study. Sci. Rep. 6:39283. doi: 10.1038/srep39283.

7. Caballero B. 2005. A nutrition paradox-underweight and obesity in developing countries. N. Engl. J.Med. 352:1514-1516.

8. Chang AM, Scheer FA, Czeisler CA. 2011. The human circadian system adapts to prior photic history. J Physiol. 589:1095-1102.

9. Christou S, Wehrens SMT, Isherwood C, Möller-Levet CS, Wu H, Revell VL, Bucca G, Skene DJ, Laing EE, Archer SN, et al. 2019. Circadian regulation in human white adipose tissue revealed by transcriptome and metabolic network analysis. Sci Rep. 9(1):2641. doi:10.1038/s41598019-39668-3. 
10. Colles SL, Dixon JB, O'Brien PE. 2007. Night eating syndrome and nocturnal snacking: association with obesity, binge eating and psychological distress. Int J Obes. 31:1722-30.

11. De la Iglesia HO, Fernandez-Duque E, Golombek DA, Lanza N, Duffy JF, Czeisler CA, Valeggia CR. 2015. Access to electric light is associated with shorter sleep duration in a Traditionally Hunter-Gatherer $\begin{array}{llll}\text { Community. } & \text { J Bo(4):342-50. }\end{array}$ doi:10.1177/0748730415590702.

12. Farr OM, Mantzoros CS. 2018. Advances at the intersection of sleep and metabolism research. Metabolism. 84:1-2.

13. Figueiro MG, Plitnick B, Rea MS. 2012. Light modulates leptin and ghrelin in sleep-restricted adults. Int J Endocrinol. 2012:530726.

14. Fonken LK, Workman JL, Walton JC, Weil ZM, Morris JS, Haim A, Nelson RJ. 2010. Light at night increases body mass by shifting the time of food intake. Proc Natl Acad Sci USA. 107(43):18664-18669.

15. Geloneze B, Repetto EM, Geloneze SR, Tambascia MA, Ermetice MN. 2006. The threshold value for insulin resistance (HOMAIR) in an admixtured population IR in the Brazilian Metabolic Syndrome Study. Diabetes Res Clin Prac. 72:219-20.

16. Geovanini GR, Lorenzi-Filho G, Paula LK, Oliveira CM, Alvim RO, Beijamini F, Negrão AB, von Schantz M, Knutson KL, Krieger JE, Pereira AC. 2019. Poor sleep quality and lipid profile in a rural cohort (The Baependi Heart Study). Sleep Medicine. 57: 30-35.

17. Instituto Brasileiro de Geografia e Estatística (IBGE). 2010. Censo Demográfico 2010: Características da População e dos Domicílios Resultados do Universo [2010 Population Census: Characteristics of Population and Households - Results of the Universe]. http://biblioteca.ibge.gov.br/visualizacao/periodicos/93/cd_2010_caract eristicas_populacao_domicilios.pdf> [accessed 2018 June 29].

18. Kearney, J. 2010. Food consumption trends and drivers. Philos. Trans. R. Soc. Lond. B Biol. Sci. 365, 2793-2807.

19. Liu X, Wu D, Qi X, Niu Y, Li W, Lu Y, Chang J. 2018. The associations between carbohydrate and protein intakes with habitual sleep duration 
among adults living in urban and rural areas. Clinical Nutrition. 37:1631e1637.

20. Lucassen EA, Zhao X, Rother KI, Mattingly MS, Courville AB, Jonge L, Csako G, Cizza G, Sleep Extension Study Group. 2013. Evening chronotype is associated with changes in eating behavior, more sleep apnea, and increased stress hormones in short sleeping obese individuals. PLoS One. 8: e56519.

21. Lunn RM, Blask DE, Coogan AN, Figueiro MG, Gorman MR, Hall JE, Hansen J, Nelson RJ, Panda S, Smolensky MH, et al. 2017. Health consequences of electric lighting practices in the modern world: A report on the National Toxicology Program's workshop on shift work at night, artificial light at night, and circadian disruption. Sci Total Environ. 607608:1073-1084.

22. McHill AW, Phillips AJK, Czeisler CA, Keating L, Yee K, Barger LK, Garaulet M, Scheer FAJL, Klerman EB. 2017. Later circadian timing of food intake is associated with increased body fat. Am J Clin Nutr. doi: 10.3945/ajcn.117.161588.

23. McMullan CJ, Schernhammer ES, Rimm EB, Hu FB, Forman JP. 2013. Melatonin secretion and the incidence of type 2 diabetes. JAMA. 309: 1388-1396.

24. Malik VS, Willet WC, Hu FB. 2013. Global obesity: trends, risk factors and policy implications. Nat. Rev. Endocrinol. 9:13-27 doi:10.1038/nrendo.2012.199.

25. Martins AJ, Vasconcelos SPV, Skene DJ, Lowden A, Moreno CRC. 2016. Effects of physical activity at work and life-style on sleep in workers from an Amazonian Extractivist Reserve. Sleep Science. 9(4):89-294.

26. Monteiro CA, Cannon G, Moubarac JC, Levy RB, Louzada LCM, Jaime PC. 2019. Freshly Prepared Meals and Not Ultra-Processed Foods. Cell Metabolism. 30: 5-6.

27. Moreno, C. R. C. et al. 2015. Sleep patterns in Amazon rubber tappers with and without electric light at home. Sci. Rep. 5:14074; doi: 10.1038/srep14074. 
28. Moreno CRC, Lowden A, Vasconcelos SP, Marqueze EC. 2016. Musculoskeletal pain and insomnia among workers with different occupations and working hours. Chronobiol Int doi:10.3109/07420528.2016.1167730.

29. Novak NL, Allender S, Scarborough P, West D. 2012. The development and validation of an urbanicity scale in a multi-country study. BMC Public Health. 12:530. doi: 10.1186/1471-2458-12-530.

30. Obayashi K, Saeki K, Iwamoto J, Okamoto N, Tomioka K, Nezu S, Ikada Y, Kurumatani N. 2012. Positive effect of daylight exposure on nocturnal urinary melatonin excretion in the elderly: a cross-sectional analysis of the HEIJO-KYO study. J Clin Endocrinol Metab. 97: 4166-4173.

31. Obayashi K, Saeki K, Kurumatani N. 2016. Ambient Light Exposure and Changes in Obesity Parameters: A Longitudinal Study of the HEIJOKYO Cohort J Clin Endocrinol Metab. 101(9):3539 -3547.

32. Obirikorang C, Osakunor DNM, Anto EO, Amponsah SO, Adarkwa OK. 2015. Obesity and Cardio-Metabolic Risk Factors in an Urban and Rural Population in the Ashanti Region-Ghana: A Comparative CrossSectional Study. PLOS ONE. doi:10.1371/journal.pone.0129494.

33. Patel SR, Malhotra A, White DP, Gottlieb DJ, Hu FB. 2006. Association between reduced sleep and weight gain in women. Am J Epidemiol. 164: 947-954.

34.Patel SR, Hu FB. 2008. Short sleep duration and weight gain: a systematic review. Obesity. 16:643-653.

35. Peschke E, Bahr I, Muhlbauer E. 2013. Melatonin and Pancreatic Islets: Interrelationships between Melatonin, Insulin and Glucagon. Int J Mol Sci. 14: 6981-7015.

36. Popkin BM. 2009. The World is Fat: The Fads, Trends, Policies, and Products That Are Fattening the Human Race. New York (NY,USA): Penguin Group.

37.Portaluppi F, Smolensky MH, Touitou Y. 2010. Ethics and Methods for Biological Rhythm Research on Animals and Human Beings, Chronobiol. Int. 27:1911-1929. 
38. Potter GD, Skene DJ, Arendt J, Cade JE, Grant PJ, Hardie LJ. 2016. Circadian Rhythm and Sleep Disruption: Causes, Metabolic Consequences, and Countermeasures. Endocr Rev. 37(6):584-608. doi:10.1210/er.2016-1083.

39. Reid KJ, Santostasi G, Baron KG, Wilson J, Kang J, Zee PC. 2014. Timing and Intensity of Light Correlate with Body Weight in Adults. PLoS ONE. 9(4):e92251. doi:10.1371/journal.pone.0092251.

40. Roenneberg T, Allebrandt KV, Merrow M, Vetter C. 2012. Social jetlag and obesity. Curr Biol. 22: 939-943.

41. Salgado-Delgado $R$, Angeles-Castellanos $M$, Saderi $N$, Buijs RM, Escobar C. 2010. Food intake during the normal activity phase prevents obesity and circadian desynchrony in a rat model of night work. Endocrinology. 151:1019-29.

42. Smith KA, Schoen MW, Czeisler CA. 2004. Adaptation of human pineal melatonin suppression by recent photic history. J Clin Endocrinol Metab. 89: 3610-3614.

43. Spiegel K, Tasali E, Penev P, Van Cauter E. 2004. Brief communication: sleep curtailment in healthy young men is associated with decreased leptin levels, elevated ghrelin levels, and increased hunger and appetite. Ann Intern Med.141:846 - 850.

44. Spiegel K, Leproult R, Van Cauter E. 1999. Impact of sleep debt on metabolic and endocrine function. Lancet. 354(9188):1435-9.

45. Tiuganji N, Nehme $P$, Marqueze EC, Isherwood CM, Martins AJ, Vasconcelos SP, Cipolla-Neto J, Lowden A, Skene DJ, Moreno CRC. 2020. Eating Behavior (Duration, Content, and Timing) Among Workers Living under Different Levels of Urbanization. Nutrients. 12: 375.

46. United Nations Human Settlements Programme. 2016. Urbanization and development: emerging futures. World Cities Report 2016. <https://unhabitat.org/wp-content/uploads/2014/03/WCR-\%20FullReport-2016.pdf> [accessed 2018 Aug 5].

47. World Health Organization. 2000. World Health Organization; Geneva. Obesity: preventing and managing the global epidemic; p. 894. Report of a WHO Consulation. WHO Technical Report Series. 
48. World Health Organization. 2015. World Health Organization; Geneva: Cardiovascular diseases

(CVDs).

<http://www.who.int/mediacentre/factsheets/fs317/en/> [accessed 2018 Aug 5].

49. Xu S, Ming J, Yang C, Gao B, Wan Y, Xing Y, Zhang L, Ji Q. 2014. Urban, semi-urban and rural difference in the prevalence of metabolic syndrome in Shaanxi province, northwestern China: a populationbased survey. BMC Public Health. 14:104.

50.Zanuto R, Siqueira-Filho MA, Caperuto LC, Bacurau RF, Hirata E, Peliciari-Garcia RA, Amaral FG, Marçal AC, Ribeiro LM, Camporez JPG, et al. 2013. Melatonin improves insulin sensitivity independently of weight loss in old obese rats. J Pineal Res. 55(2):156-65. 
Table 1 - Age and metabolic parameters among rural $(n=22)$ and town $(n=20)$ dwellers.

\begin{tabular}{lccl}
\hline Variables & $\begin{array}{l}\text { Town (n=20) } \\
\text { mean (SD) }\end{array}$ & $\begin{array}{l}\text { Rural (n=22) } \\
\text { mean (SD) }\end{array}$ & P-value (T- test) \\
\hline Age (years) & $43.50(12.0)$ & $42.00(18.0)$ & $0.332^{1}$ \\
BMI (kg/m²) & $28.06(4.2)$ & $24.95(3.3)$ & $\mathbf{0 . 0 1 1}$ \\
Waist (cm) & $97.05(10.9)$ & $86.40(9.4)$ & $\mathbf{0 . 0 0 2}$ \\
Fat (\%) & $25.07(6.0)$ & $19.23(5.4)$ & $\mathbf{0 . 0 0 2}$ \\
Visceral fat (\%) & $10.05(3.7)$ & $7.72(3.4)$ & $\mathbf{0 . 0 4 2}$ \\
Muscle (kg) & $58.28(7.1)$ & $51.69(5.6)$ & $\mathbf{0 . 0 0 2}$ \\
Metabolic age (years) & $50.00(20.0)$ & $34.50(20.0)$ & $\mathbf{0 . 0 0 6}{ }^{1}$ \\
Triglycerides (mg/dL) & $136.00(113.0)$ & $130.50(32.0)$ & $0.200^{1}$ \\
Insulin (uUI/mL) & $10.99(7.5)$ & $4.42(3.3)$ & $\mathbf{0 . 0 0 3}{ }^{1}$ \\
Total cholesterol (mg/dL) & $157.00(38.0)$ & $114.00(28.0)$ & $0.120^{1}$ \\
HDL-cholesterol (mg/dL) & $40.21(10.2)$ & $43.54(10.3)$ & 0.305 \\
LDL-cholesterol (mg/dL) & $87.00(43.0)$ & $75.40(33.0)$ & $0.448^{1}$ \\
VLDL-cholesterol (mg/dL) & $34.35(11.6)$ & $31.22(11.3)$ & 0.403 \\
Fasting glucose (mg/dL) & $88.52(14.2)$ & $79.36(12.5)$ & $\mathbf{0 . 0 3 5}$ \\
HOMA-IR & $2.11(1.0-3.4)$ & $0.90(0.5-1.3)$ & $\mathbf{0 . 0 0 1}{ }^{1}$ \\
\hline
\end{tabular}

1 Due to non-normal distribution, the median was calculated and Mann Whitney tests conducted. 

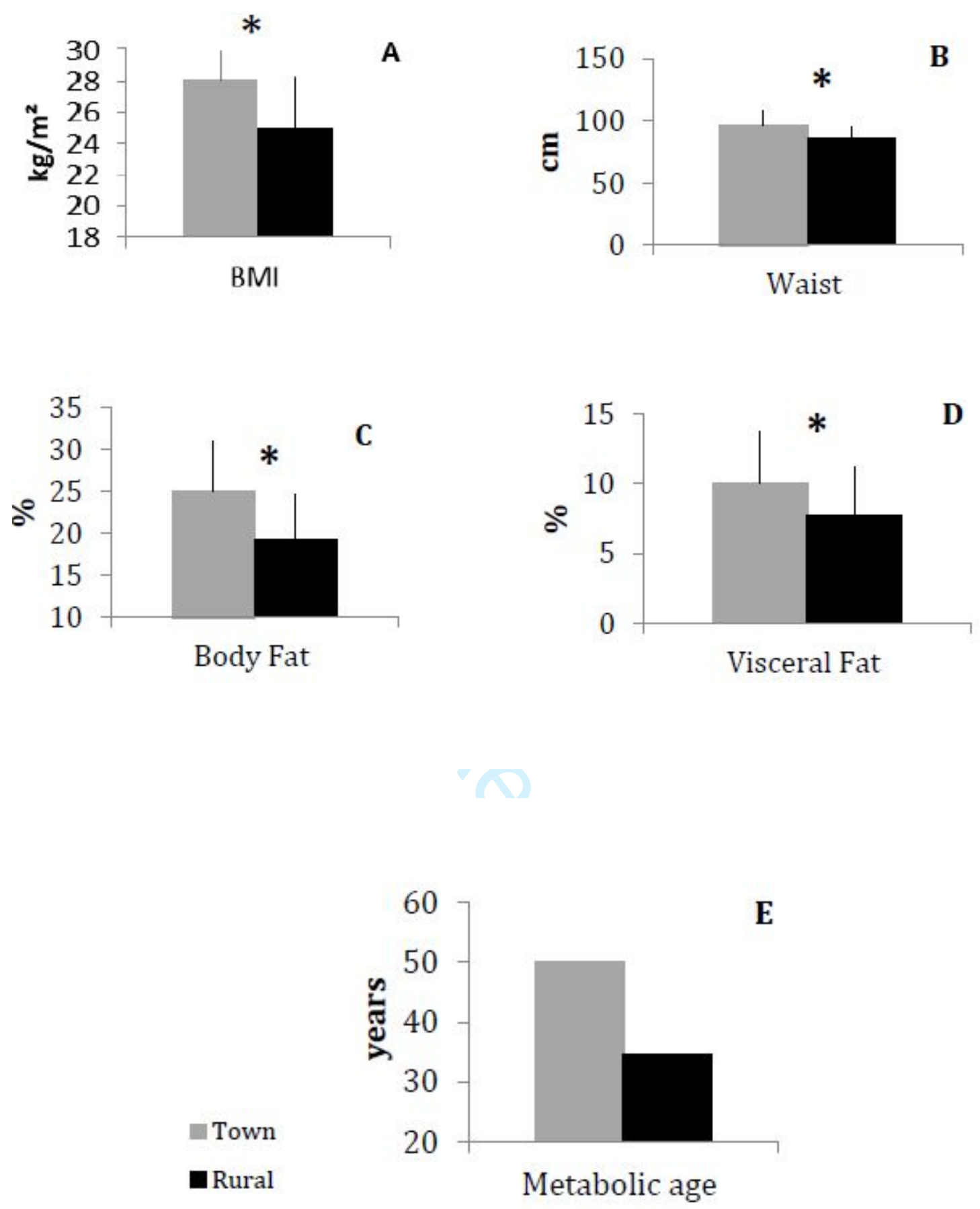

FIGURE 1 
A

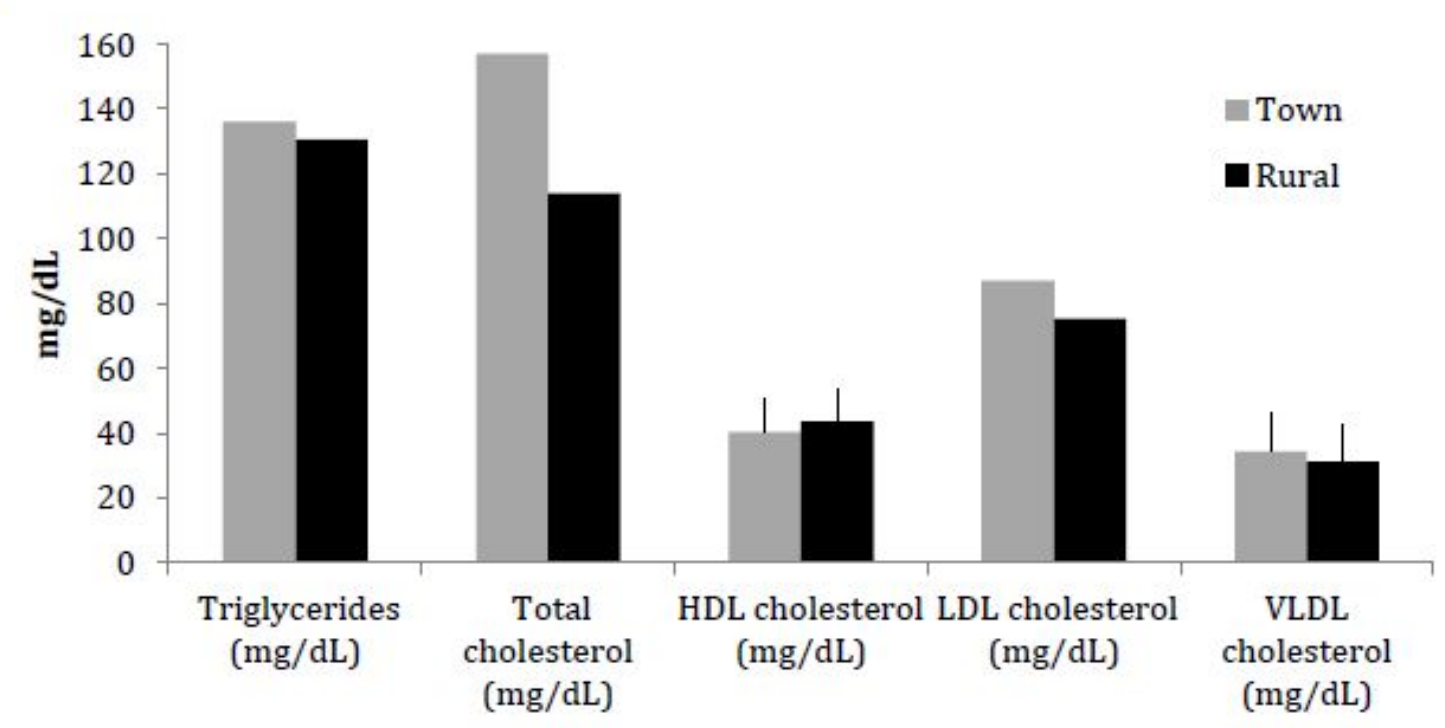

B

C
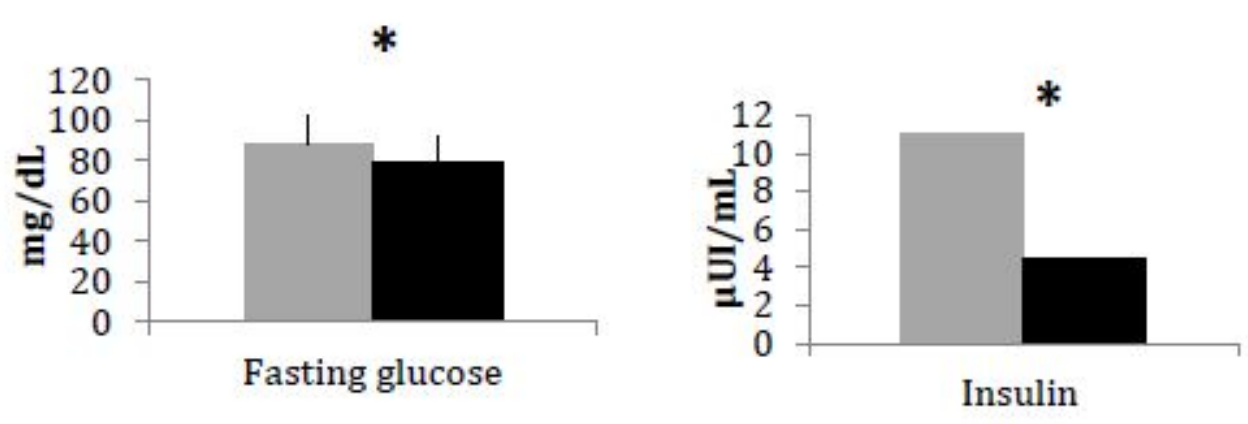

D

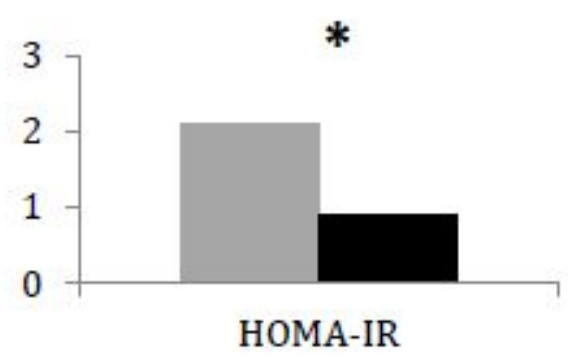

FIGURE 2 

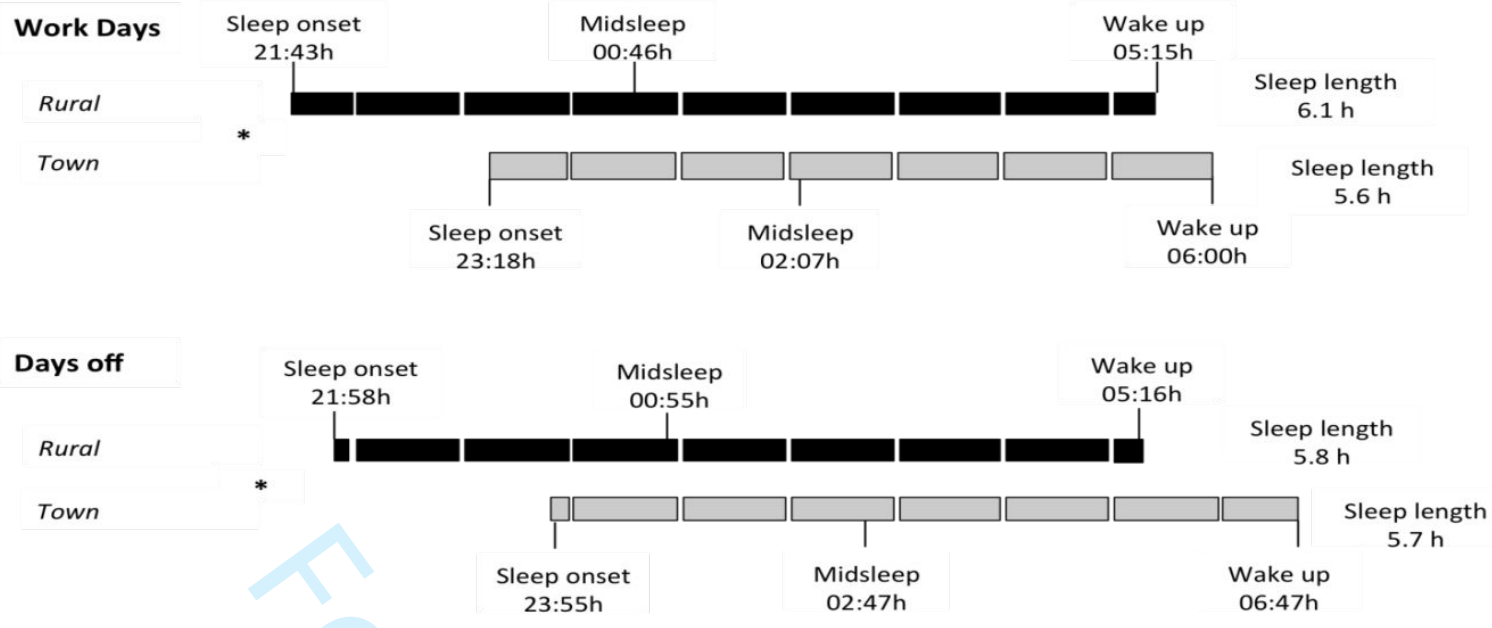

*p<0.05 


\section{CAPTIONS}

Figure 1. Mean ( \pm SD) fasting lipid profile (A), glucose (B), insulin (C) and HOMA-IR (D) among town $(n=20)$ and rural $(n=22)$ dwellers. Student's t test or Mann-Whitney test. ${ }^{*} \mathrm{p}<0.05$.

Figure 2. Anthropometric variables (mean $\pm \mathrm{SD})$ among town dwellers $(\mathrm{n}=20)$ and rural $(\mathrm{n}=22)$ dwellers. Student's t test: BMI (A), waist (B), body fat (C) and visceral fat (D). Mann-Whitney test: metabolic age $(\mathrm{E}) ;{ }^{*} \mathrm{p}<0.05$.

Figure 3. Sleep patterns (sleep onset, midsleep, wake up time and sleep duration) on work days and days off among rural $(n=22)$ and town $(n=20)$ dwellers. Black: rural dwellers; Grey: town dwellers. ${ }^{*} \mathrm{p}<0.05$ in all sleep parameters shown. 


\section{Supplemental material}
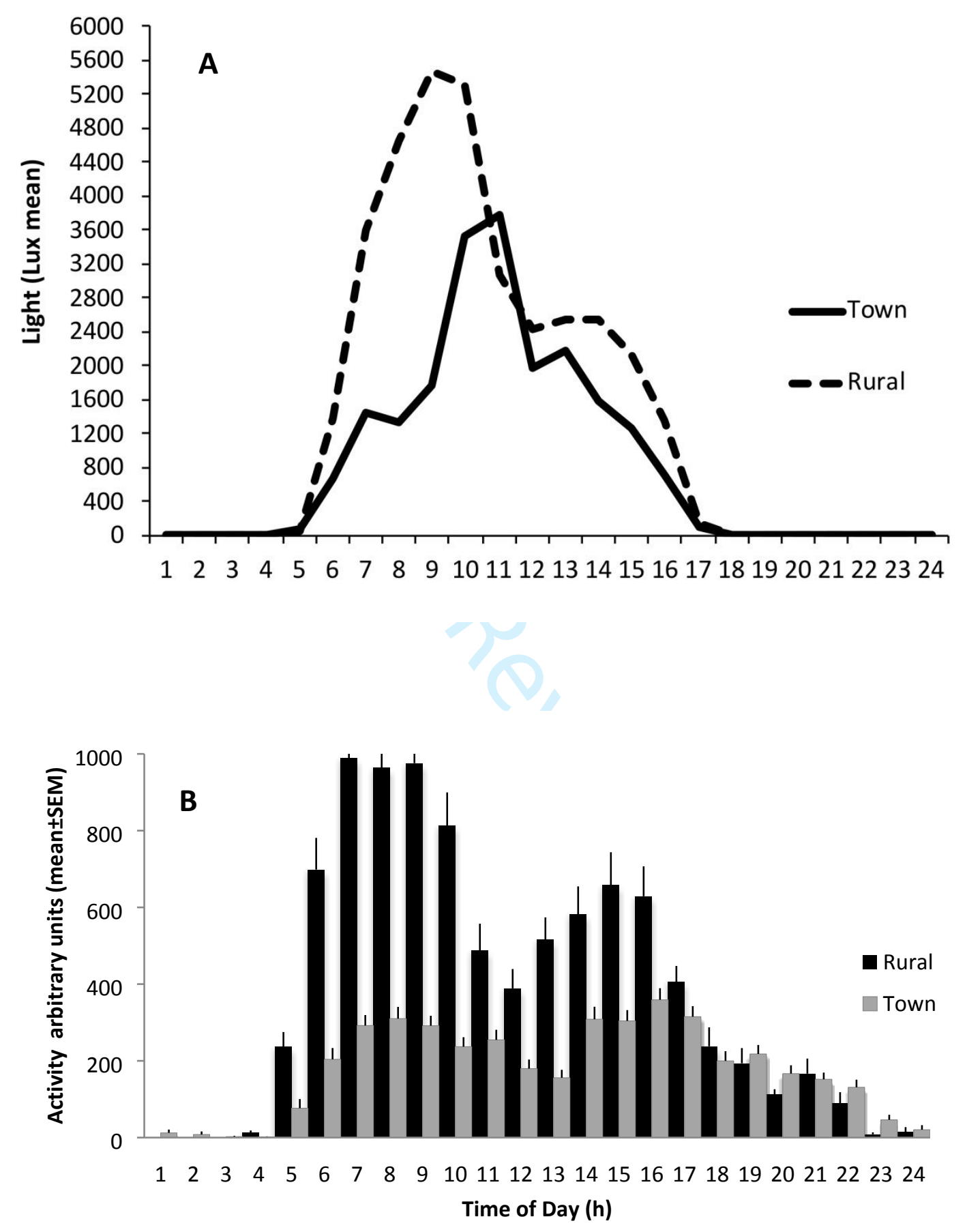

Figure 1. Light (A) (mean lux) and activity levels (B) (mean units \pm SEM) per hour across the $24 \mathrm{~h}$ day during work days of rural $(\mathrm{n}=22)$ and town $(\mathrm{n}=20)$ participants. Repeated measures ANOVA showed significant differences in activity levels ( $F=17.81$, $p=0.0003 ; F=3.20, p=0.0036)$ and light exposure $(F=10.18 p=0.0041 ; F=10.49$, $p<0.0001)$ between the two groups and time of day. 

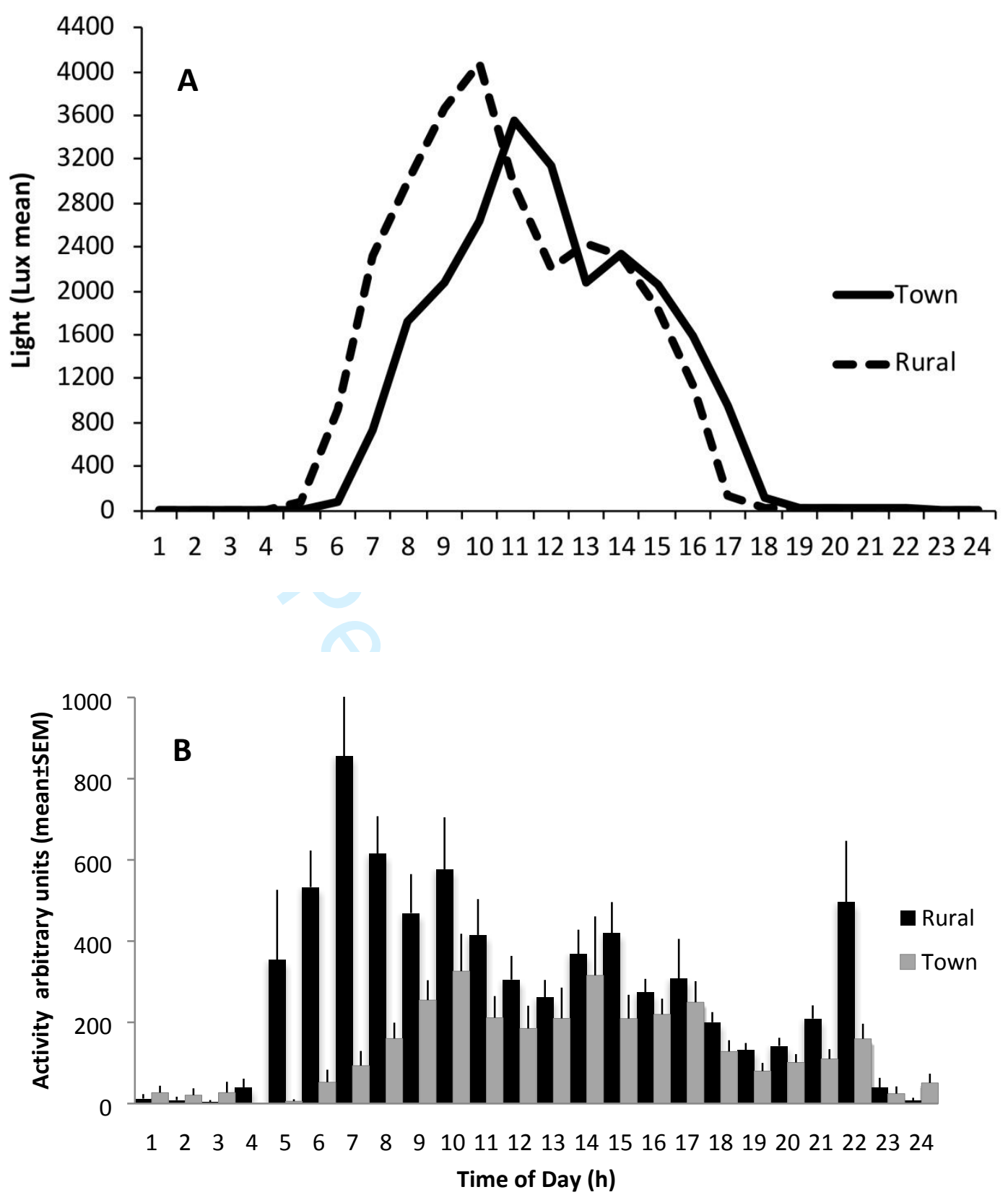

Figure 2. Light (A) (mean lux) and activity levels (B) (mean units \pm SEM) per hour across the $24 \mathrm{~h}$ day during days off of rural $(\mathrm{n}=22$, black) and town $(\mathrm{n}=20$, grey) participants. Repeated measures ANOVA show significant differences in activity levels $(F=15.79, p=0.0006)$ and no differences in light exposure $(F=0.40 p=0.5322)$ among the two groups. Significant time of day differences were found in activity levels $(F=2.19, p=0.0330)$ and light exposure $(F=10.77, p<0.0001)$. 